University of Wollongong

Research Online

Faculty of Engineering and Information

Faculty of Engineering and Information

Sciences - Papers: Part A

Sciences

$1-1-2016$

\title{
A laboratory investigation to assess the functioning of railway ballast with and without geogrids
}

Syed Khaja Karimullah Hussaini

Indian Institute of Technology Patna, kkhs545@uowmail.edu.au

Buddhima Indraratna

University of Wollongong, indra@uow.edu.au

Jayan S. Vinod

University of Wollongong, vinod@uow.edu.au

Follow this and additional works at: https://ro.uow.edu.au/eispapers

Part of the Engineering Commons, and the Science and Technology Studies Commons

Research Online is the open access institutional repository for the University of Wollongong. For further information contact the UOW Library: research-pubs@uow.edu.au 


\title{
A laboratory investigation to assess the functioning of railway ballast with and without geogrids
}

\author{
Abstract \\ Understanding the complex load transfer mechanism and the subsequent accumulation of deformation in \\ ballast and subballast layers under repeated wheel loading is essential to design resilient rail tracks. \\ Large-scale cyclic tests have been conducted on railroad ballast instrumented with optical based fibre \\ Bragg grating (FBG) sensors, LVDTs, pressure plates and the settlement pegs to explore the role of \\ geogrid and its interaction with ballast in improving the track performance. Latite basalt and geogrids \\ with different aperture sizes were used for the investigations. The laboratory experimental results indicate \\ that the geogrid inclusions enhance track performance by arresting the lateral spreading of ballast and \\ thereby significantly reducing the extent of its vertical settlement. In contrast, the reinforcement of ballast \\ with geogrid has only a marginal effect on reducing the settlement in the subballast layer. The results also \\ show that geogrid minimises the amount of particle breakage, the effectiveness of which is governed by \\ its placement position, with lowest breakage occurring when the geogrid is placed at a location $130 \mathrm{~mm}$ \\ above the subballast. In addition, geogrids also reduce the extent of vertical stress in the subgrade soil. \\ The laboratory test results establish beyond doubt the effectiveness of FBG sensing system in capturing \\ the ballast movement under cyclic loading.

\section{Disciplines} \\ Engineering | Science and Technology Studies

\section{Publication Details} \\ Hussaini, S., Indraratna, B. \& Vinod, J. S. (2016). A laboratory investigation to assess the functioning of \\ railway ballast with and without geogrids. Transportation Geotechnics, 6 45-54.
}

This journal article is available at Research Online: https://ro.uow.edu.au/eispapers/5361 


\title{
A LABORATORY INVESTIGATION TO ASSESS THE FUNCTIONING OF RAILWAY BALLAST WITH AND WITHOUT GEOGRIDS
}

\author{
*Syed Khaja Karimullah Hussaini (PhD) \\ Assistant Professor, \\ Department of Civil and Environmental Engineering, \\ Indian Institute of Technology Patna, \\ Patna, Bihar 801103 \\ Phone +91-612-3028196 \\ Email: hussaini@iitp.ac.in \\ Buddhima Indraratna (PhD, FTSE, FIEAust, FASCE, FGS, DIC) \\ Professor of Civil Engineering and Research Director, \\ Centre for Geomechanics and Railway Engineering, \\ University of Wollongong, \\ Wollongong City, NSW 2522, Australia \\ PH (+61) 24221 3046; FAX (+61) 24221 3238; \\ Email: indra@uow.edu.au \\ Jayan S. Vinod (PhD) \\ Senior Lecturer in Civil Engineering, \\ Centre for Geomechanics and Railway Engineering, \\ University of Wollongong, \\ Wollongong City, NSW 2522, Australia \\ Email:vinod@uow.edu.au \\ *Corresponding author \\ Contact address \\ Syed Khaja Karimullah Hussaini (PhD) \\ Assistant Professor, \\ Department of Civil and Environmental Engineering, \\ Indian Institute of Technology Patna, \\ Patna, Bihar 800013 \\ Phone +91-612-2260086 \\ Email: hussaini@iitp.ac.in \\ No. of Words: 6254 \\ No. of Tables: 4 \\ No. of Figures: 7
}

Keywords: geogrid, lateral spreading of ballast, FBG sensing system, ballast breakage index, cyclic loading. 


\title{
A LABORATORY INVESTIGATION TO ASSESS THE FUNCTIONING OF RAILWAY BALLAST WITH AND WITHOUT GEOGRIDS
}

Syed Khaja Karimullah Hussaini; Buddhima Indraratna; and J.S. Vinod

\begin{abstract}
Understanding the complex load transfer mechanism and the subsequent accumulation of deformation in ballast and subballast layers under repeated wheel loading is essential to design resilient rail tracks. Large-scale cyclic tests have been conducted on railroad ballast instrumented with optical based fiber Bragg grating (FBG) sensors, LVDTs, pressure plates and the settlement pegs to explore the role of geogrid and its interaction with ballast in improving the track performance. Latite basalt and geogrids with different aperture sizes were used for the investigations. The laboratory experimental results indicate that the geogrid inclusions enhance track performance by arresting the lateral spreading of ballast and thereby significantly reducing the extent of its vertical settlement. In contrast, the reinforcement of ballast with geogrid has only a marginal effect on reducing the settlement in the subballast layer. The results also show that geogrid minimises the amount of particle breakage, the effectiveness of which is governed by its placement position, with lowest breakage occurring when the geogrid is placed at a location $130 \mathrm{~mm}$ above the subballast. In addition, geogrids also reduce the extent of vertical stress in the subgrade soil. The laboratory test results establish beyond doubt the effectiveness of FBG sensing system in capturing the ballast movement under cyclic loading.
\end{abstract}

Keywords: geogrid, lateral spreading of ballast, FBG sensing system, ballast breakage index, cyclic loading.

\section{Introduction}

The emergent requirement for better and efficient rail transport system both in terms of increased freight capacity and greater train speeds inherently place additional stresses on ballast. The repeated application of stress arising due to the passage of trains degrades and fouls the ballast which directly contributes to differential track settlement and track misalignment, thereby affecting the track stability and safety. In addition, the low in-situ confining pressure (i.e. 10-30 $\mathrm{kPa}$ ) prompts the lateral spreading of ballast that further deteriorates the track condition (Baessler and Rucker 2003; Selig and Waters 1994).The recent study conducted by Dash and Shivadas (2012) also highlighted the lateral flow of ballast as one of the serious track problems. The practical implications of these track 
problems are to either impose speed restrictions on the affected track segments or to repair the concerned portions by replacing the ballast. However, the imposition of speed restrictions contradicts the very idea of introducing high-speed trains, and hence is not an acceptable solution. Moreover, repairing the tracks that involves ballast replacement and correcting the track alignment is a costly exercise that consumes millions of dollars every year worldwide. In this view, it is necessary to stabilise the ballasted rail tracks by means of geosynthetics so that they can carry high-speed trains without experiencing any major problem.

In the recent past, several studies have described the cyclic behaviour of geosyntheticreinforced ballast using the large-scale testing facilities (e.g. Bathurst and Raymond 1987; Raymond and Bathurst 1987; Nancey et al. 2002; Indraratna et al. 2006; Indraratna et al. 2012). Raymond and Bathurst (1987) commented that inclusion of a biaxial geogrid within the ballast layer lead to a decrease in permanent vertical deformations of up to $50 \%$ after 100,000 load cycles. Moreover, the number of load cycles required to cause a permanent vertical deformation of $50 \mathrm{~mm}$ increased by a factor of ten (10) when a geogrid was used. Bathurst and Raymond (1987) concluded that the effect of reinforcement in reducing the permanent deformations of ballast is more pronounced in the case of tracks laid on soils with a relatively low California Bearing Ratio (CBR) values. Similarly, Matharu (1994) has reported reductions in settlement when a geogrid was used in ballasted rail track. The field studies carried by Indraratna et al. (2010) also confirmed the effectiveness of geosynthetics in augmenting the track performance. The geogrid reinforcement of ballast also reduces the extent of particle breakage (Indraratna et al. 2006, and Fernandes et al. 2008).

The aforementioned benefits of geogrid predominantly stem from the interlocking of ballast particles within the geogrid apertures. Therefore, any improvement in the deformation and degradation characteristics of ballast depends on the degree of ballast-geogrid interaction. Moreover, the effect of geogrid due to its planar geometry is expected to reduce with distance away from its placement location. Further, the internal deformations in ballast that occur as a result of train induced vibrations are yet to be studied in detail. Therefore, the current study was carried out on geogrid-reinforced ballast using the large-scale process simulation apparatus (LPSA) to gain insight into the interaction mechanism at ballast-geogrid interface and its implications on the track behaviour. 


\section{Large-scale laboratory tests on ballast with and without geogrids}

\section{Large-scale process simulation apparatus (LPSA)}

The laboratory tests were conducted using a large-scale process simulation apparatus (LPSA) (Indraratna et al. 2013). It can simulate a section of track with plan dimensions of $800 \mathrm{~mm}$ long by $600 \mathrm{~mm}$ wide. The middle segment of one of the shorter side walls comprises of five independently movable plates $(600 \mathrm{~mm}$ x $64 \mathrm{~mm}$ x $25.5 \mathrm{~mm})$ assembled vertically with a small gap of $1 \mathrm{~mm}$ between each plate to allow their free lateral movement upon loading (Figure 1a). The shorter dimension of the box (i.e. $600 \mathrm{~mm}$ ) represents the centre-to-centre spacing between the sleepers while its longer dimension (i.e. $800 \mathrm{~mm}$ ) represents the width of the loaded track (Indraratna et al. 2013). Test chambers of similar or smaller dimensions (having different side wall arrangements) were also successfully used in the past by several researchers (Mc. Dowell et al. 2004a, 2004b; Chen 2013) to study the role of geogrid on ballast behaviour.

\section{Materials used and the testing methodology adopted}

The test specimen comprised of a subballast layer of $150 \mathrm{~mm}$ at the bottom of the test chamber overlain by a $325 \mathrm{~mm}$ thick layer of ballast that was compacted in three layers using a vibrating plate to achieve a target field density of $1550 \mathrm{~kg} / \mathrm{m}^{3}$. To minimize particle breakage during vibration, a $5 \mathrm{~mm}$ thick rubber pad was placed underneath the vibrator. Fresh latite basalt from Bombo quarry, New South Wales, Australia was used for the laboratory investigations. The maximum and mean particle sizes $\left(D_{\max }\right.$ and $\left.D_{50}\right)$ of ballast used in the study were $53 \mathrm{~mm}$ and $35 \mathrm{~mm}$ respectively. The coefficient of uniformity, $C_{u}$ of ballast was 1.87. The ballast specimens conformed to AS 2758.7, and also satisfied the revised recommendations proposed by Indraratna et al. (2004) that the value of $C_{u}$ should range from 1.5 to 2.6 to possess sufficient strength and permeability. The void ratio $(e)$ of ballast samples was 0.74 . On the other hand, the maximum and mean particle sizes $\left(D_{\max }\right.$ and $\left.D_{50}\right)$ of subballast were $19 \mathrm{~mm}$ and $0.5 \mathrm{~mm}$ respectively. The coefficient of uniformity, $C_{u}$ of subballast was 5. The particle size distribution (PSD) of both the ballast and the subballast used in this study is shown in Figure 1(b). An assembly of sleeper (700 mm long) and rail section was placed above the load-bearing ballast and the space around the sleeper was filled with crib ballast up to $150 \mathrm{~mm}$ thick (Figure 1a). All the samples were prepared in a similar manner except a layer of geogrid (G1 through G4: Table 1) was placed at either (a) $z=0 \mathrm{~mm}$ or (b) $z=65 \mathrm{~mm}$, where $z$ is the distance above the subballast-ballast interface. Settlement pegs were installed at the subballast-ballast interface and at the sleeper-ballast interface to 
record the vertical settlement of ballast and subballast upon loading. A photograph of the ballast sample with settlement pegs installed in the test apparatus ready for testing is shown in Figure 2(a). A sample geogrid used in the current study is shown in Figure 2(b).

A predetermined load was applied to the rail-sleeper assembly to create a maximum vertical stress of $460 \mathrm{kPa}$ on the top of ballast layer. This applied vertical stress is representative of the maximum contact stress generated due an axle load of 25 tons (Indraratna et al. 2011). Further, in accordance with the in-situ confining pressure of 10-30 kPa (Indraratna et al. 2010\&2011), a lateral pressure of $10 \mathrm{kPa}$ (imitating the effect of shoulder ballast along with its slope) was applied using server-controlled static actuators onto the side wall comprising of five movable plates. Le Pen (2008), and Le Pen and Powrie (2011) have also reported similar values of confining pressure considering the effect of the shoulder ballast. Moreover, the field studies carried out by Indraratna et al. (2010 and 2011) for a typical railway track (300 mm ballast depth), illustrated that the confining pressure of the ballast would remain almost constant along its depth. In this context, the application of lateral pressure of $10 \mathrm{kPa}$ on the movable plates is realistic. The lateral movement of these movable plates was continuously recorded by means oflinear variable differential transformers (LVDTs), while the other walls of the test apparatus were held fixed to simulate the real track conditions. Tests were conducted at a loading frequency of $20 \mathrm{~Hz}$ and up to 250000 load cycles and were halted at selected number of load cycles (i.e. $N=1 ; 100 ; 1000 ; 3000 ; 5000 ; 10,000 ; 30,000 ; 50,000$; 100,000 and 200,000) to record the readings from the settlement pegs. The ballast specimen was recovered from the test apparatus and sieved at the end of each test to evaluate the change in gradation and to quantify the breakage of particles; thereafter the used ballast was discarded. Further details on test equipment and the testing procedures can be found in Indraratna et al. (2013) and Hussaini et al. (2015a).

\section{Instrumentation to capture internal lateral strains in ballast and those at the ballast boundary}

The five independently movable plates of the LPSA apparatus allow the free lateral movement of ballast, thereby realistically simulating the ballast behavior in the laboratory. The LVDTs were attached to these five movable plates to capture the lateral strain variation along the ballast depth. While this technique can be conveniently used to measure lateral displacements at the ballast boundary, they run the risk of being damaged when placed within ballast. Therefore, there is a need to use a thin and flexible sensing system that can record the 
internal displacements in ballast while maintaining the ballast properties unchanged. The optical-Fiber Bragg Grating sensors (FBGs) due to their high accuracy, reliability and flexibility may be used for achieving this objective. Moreover, the polyamide coating to the optical fiber is anticipated to provide resistance against the grinding motion of particles, thus minimizing the risk of damage to the optical fibres when used in ballast. This is in sharp contrast to the conventional strain gauges that are vulnerable to damage both during the specimen placement and the actual testing (Rowe and Gnanendran 1994). In comparison to the conventional electric strain gauges, the use of optical-FBG sensors have a number of obvious advantages such as (a) their ability to accurately capture the strains owing to their high sensitivity and resolution, fast response and (b) their immunity to electromagnetic and electrical signals (Zhu 2009; Mihailov 2012).

In the recent past, the FBG sensing system was successfully used in the structural health monitoring (Liehr et al. 2008; Guo et al. 2011) and in monitoring the slope stability (Dijcker et al. 2011; Nöther et al. 2012). In railway engineering, it was used to monitor the strains induced in rails, and for estimating the weight and speed of trains (Lee et al. 2004; Yoon et al. 2011). A unique characteristic of optical sensing technology is that the FBG strains can be monitored, without any alterations in them, even from about 50-100 km away from the location of sensors (Tam et al. 2007; Fernandez-Vallejo et al. 2011). Therefore, to measure the variation of internal lateral strain along the ballast depth, a sensing sheet was made by attaching four optical fibers with each containing one FBG (having a sensor length of $10 \mathrm{~mm}$ ) to a thin and flexible polymeric sheet (Figure 1a). Figure 2(c) depicts the optical fiber with a FBG sensor embedded in it. The optical fibers were glued within the grooves of the polymeric sheet (475 $\mathrm{mm}$ long, $100 \mathrm{~mm}$ wide and $2 \mathrm{~mm}$ thick) by means of Cyanoacrylate adhesive, and were left undisturbed for some time for the adhesive to form a bond between fiber and the sheet. The sensing sheet was installed in the test chamber $400 \mathrm{~mm}$ away from the movable side wall (i.e. at mid-length of the sleeper) and just adjacent to the rail, with intent to capture internal ballast movement in the immediate vicinity of the rail. The placement location of the FBGs above the subballast, as well as their wavelengths is summarized in Table 2. The FBG data was demodulated by means of a dynamic 4-channel optical sensing interrogator (Si425) and was recorded at a frequency of $1.25 \mathrm{~Hz}$. An Ethernet connection was used for the automatic data communication between the interrogator and the computer (Micron Optics Inc. 2007). 


\section{Operating principle of FBG sensors}

An optical fiber is a flexible fiber made of glass or plastic, designed to guide light along its length by total internal reflection. Typically, FBG is formed by exposing the core of an optical fiber to an intense Ultraviolet interference to cause periodic changes of the refractive index. This grating structure results in the reflection of the light at a specific narrowband wavelength, known as the Bragg wavelength. The Bragg wavelength is a function of the refractive index of the fiber core and the grating period, and this condition is represented by Equation 1. The operating principle of fiber Bragg grating (FBG) sensors involves monitoring of the wavelength shift in the reflected wavelength spectrum, and then converting it to strain in FBG sensor by using the relevant calibration charts (Hussaini et al. 2015b).

$$
\lambda_{B}=2 n_{e} \Lambda
$$

Where, $\lambda_{b}$ is the Bragg wavelength of the FBG, $n_{e}$ is the effective refractive index of the fiber core and $\Lambda$ is the grating period.

\section{Results and discussion}

To correlate the laboratory data to the actual rail track behaviour, the number of load cycles $(N)$ has been suitably converted to the track operation time as per Equation 2 (Selig and Waters 1994).

$$
C_{m}=\frac{10^{6}}{\left(A_{t} \times N_{a}\right)}
$$

Where $C_{m}$ is the number of load cycles/MGT (million gross tons); $A_{t}$ is the axle load in tons; and $N_{a}$ is the number of axles/load cycle.

For an annual traffic tonnage of 25 MGT and four axles per load cycle, an axle load of 25 tons imparts 250000 load cycles per year of track operation. Based on this criterion, the 250000 load cycles considered in this current study corresponds to one year of track operation.

\section{The lateral strains in ballast with number of load cycles (N)}

The change in FBG strains $(\mu \varepsilon)$ with number of load cycles $(N)$ for unreinforced and ballast reinforced with geogrid G4 (placed at $z=0 \mathrm{~mm}$ ) is shown in Figure 3. The lateral 
displacements in ballast as obtained from the conventional LVDTs attached to the movable plates are also shown here for the sake of comparison. Here, the data from FBG-1 (bottom sensor) and FBG-4 (topmost sensor) are compared with the movement of bottom and top plates, respectively. On the other hand, the data from FBG-2 andFBG-3 are compared with the average of movement of plates 2-3 and 3-4, respectively.Figure 3 reveals that a major portion of the FBG strains and also displacements from LVDTs develop during the initial 50000 load cycles indicating that particles tend to spread laterally during this loading regime. A similar observation with regards to strains in FBG sensors for the ballast reinforced with geogrid G3 was made by Hussaini et al. (2015b). A closer look at Figure 3 depicts that both the FBG strains and the lateral displacements from LVDTs, in a macroscopic sense, follow a similar strain evolution pattern with load cycles $(N)$. This strain evolution pattern is also in line with that reported in the past by several researchers based on the conventional data acquisition techniques (Raymond and Bathurst 1994; Lackenby et al. 2007; Aursudkij et al. 2009). The occasional sharp rise and fall in FBG strain (Figure 3c) is consistent with the research results available in the literature (Zhu 2009; Weng and Wang 2011) and is due to the localized rearrangement of particles (e.g. sudden loss of interlock between particles) during the loading, which the FBG sensors could successfully capture owing to their high resolution. As expected, the reduction in deformations in ballast due to the geogrid inclusion is also clearly evident from both the FBG as well as the LVDT data. This clearly underscores the capability of FBG sensing system in accurately capturing the internal strains in ballast at both initial and final stages of loading. The absence of fluctuations in FBG strains in Figure 3 for a certain range of load cycles may be attributed to the lack of ballast movement in the vicinity of FBG due to strong inter-particle interlocking in a localised zone. Moreover, it is seen from Figure $3 \mathrm{~d}$ that the effect of geogrid in imposing non-displacement boundary conditions at the ballast-geogrid interface and hence inhibiting the lateral spread of ballast exists even after 250000 load cycles (i.e. one year of track operation). Even at locations away from the geogrid (Figure 3a), the lateral displacements in ballast from both the FBG sensors and LVDTs remain fairly constant after 50000 load cycles until the end of loading. This indicates that ballast continues to possess sufficient strength and does not show any signs of fatigue induced damage, and hence can perform intended function of load distribution without any portion of it requiring replacement.

While the LVDTs could record only the overall lateral strain behaviour of ballast, the FBG sensing system owing to its higher sensitivity and resolution also succeeded in capturing the 
minor variations in strain that arises because of the vibrations in ballast due to high-frequency cyclic loading (Figure 3). These sorts of minor fluctuations could in the past be captured only by DEM based numerical simulations (e.g. Ferellec and McDowell 2010). However, the use of FBG sensors has made it possible to record the minor fluctuations from laboratory tests as well. This attribute of FBG sensing system makes it a viable alternative to accurately obtain the internal deformations in ballast, and hence can effectively be utilised in future studies to capture the effect of increasing train speed on the vibrations in ballast.

\section{Vertical settlement of ballast and subballast layers}

A total of eight settlement pegs were placed at the top of the load bearing ballast and at the subballast-ballast interface to record the vertical settlements in the subballast and ballast layers. While the readings from the bottom settlement pegs directly gives the vertical settlement of subballast layer, the difference of readings from the top and bottom layers of settlement pegs gives the total vertical settlement of ballast. The average vertical settlement of the ballast and the subballast layers for unreinforced and geogrid-reinforced ballast (G3 and G4) are shown in Figure 4a. It is evident from Figure 4a that both unreinforced and geogrid-reinforced ballast (G3 and G4) follow a similar pattern of vertical settlement with number of load cycles $(N)$, with rapid deformations occurring within the first 50000 load cycles. The geogrid G4, owing to its favourable aperture size in comparison to $D_{50}$ of $35 \mathrm{~mm}$, performs better than G3. This is primarily attributed to the level of interaction at the ballastgeogrid interface as described earlier by Indraratna et al. (2012). The settlement pattern for ballast reinforced with other geogrids is also the same and is therefore not shown here for the sake of brevity. The settlement of ballast recorded from the current study follows a similar trend to that measured from the field by Indraratna et al. (2010). For loading beyond 50000 cycles, ballast attains a stable packing and hence the total vertical settlement remains fairly constant (Figure 4a). These observations, in a practical sense, imply that intense rearrangement of particles occurs within the first two months of track operation (for a track with annual traffic tonnage of $25 \mathrm{MGT}$ ) when the ballast is in the loosest state. As evident, all the ballast samples including the unreinforced one could successfully survive 250000 cycles of loading without any sudden destabilisation (Figure 4a). These findings signify that a rail track can effectively support an axle load of 25 tonnes moving at a speed of $150 \mathrm{~km} / \mathrm{h}$ even for a low in-situ confining pressure of $10 \mathrm{kPa}$, albeit with higher associated deformations. The inclusion of geogrid (G4) has successfully reduced the total vertical settlements in ballast from $23.5 \mathrm{~mm}$ to $13.2 \mathrm{~mm}$. Moreover, the number of load cycles required to cause a given 
vertical settlement of about $13 \mathrm{~mm}$ increases from 100 in case of unreinforced ballast to 10000 and 200000 load cycles for ballast reinforced with G3 and G4 respectively. Further, the vertical settlement of both the unreinforced ballast and that reinforced with different geogrids with number of load cycles $(N)$ is established to be governed by a logarithmic relationship as expressed in Equation 3.

$$
\text { Settlement in ballast }(\mathrm{mm})=\propto \times \ln (N)+\beta
$$

Where $\alpha$ and $\beta$ are the empirical constants; and $N$ is the number of load cycle. The values of $\alpha$ and $\beta$ for ballast reinforced with different geogrids are summarized in Table 3.

The vertical settlements in subballast layer also follow a trend akin to that of ballast except that it undergoes only a marginal vertical settlement of $4.33 \mathrm{~mm}$ (Figure $4 \mathrm{~b}$ ) in comparison to a total vertical settlement of $23.5 \mathrm{~mm}$ in case of unreinforced ballast. While the total maximum vertical strain in ballast is about $7.25 \%$, the maximum vertical strain in subballast is only about $3 \%$. This may be attributed to the reduced stresses acting at the subballastballast interface (as evident from Figure 7) topped up by the relatively higher density of subballast layer that eventually leaves a lesser room for particle rearrangement. Upon reinforcing the overlying ballast layer with geogrids G3 and G4, the settlement of subballast reduces to 3.01 and $2.82 \mathrm{~mm}$ respectively. The reinforcement of ballast with other geogrids also produced similar marginal effect on settlement of subballast, but is not shown here for the sake of brevity. It is to be clarified here that in the current study geogrid was placed either within ballast or at the base of ballast, and the subballast layer was free from any reinforcement. These experimental observations indicate that it is more beneficial to reinforce the ballast layer rather than subballast, as the latter undergoes minor deformations only.

\section{Influence of loading on the PSD of ballast}

The ballast samples were sieved after the tests to evaluate the changes in PSD because of the applied cyclic loading. The final PSD of unreinforced and geogrid-reinforced ballast (G3) is shown in Figure 5. The coefficient of uniformity $\left(c_{u f}\right)$ of different ballast samples after the testing ranged from 1.89-1.94 in comparison to an initial $c_{u}$ of 1.87 (Table 4). Their corresponding ballast breakage indices (BBI, after Indraratna et al. 2005) ranged from 4.6 to $11.0 \%$, as reported by Indraratna et al. (2013). The generation of fines of different sizes as a result of particle breakage makes the sample well-graded, with the ones undergoing higher 
particle breakage exhibiting a higher value of $c_{u f}$. However, the $c_{u f}$ value of 1.94 obtained after 250000 load cycles is still less than the permissible upper limit of 2.6 to be able to possess sufficient permeability, as recommended by Indraratna et al. (2004). In other words, the particle degradation that occurs with loading (i.e. passage of trains) is not high enough on its own to cause any major permeability problem in tracks. This is further substantiated by the fact that the final void ratio $\left(e_{f}\right)$ of unreinforced ballast is 0.65 , which is only marginally less than its initial value of 0.74 . The sample reinforced with geogrid G4 exhibits a still higher final void ratio of 0.71 (Table 4 ). These results certainly point out that although the breakage of particles alone does not critically affect the ballast permeability, still geogrid plays a role in maintaining the voids in ballast that are essential for the quick drainage of water in case of flash floods.

\section{Optimum geogrid placement position to minimise particle breakage}

It is well known that rearrangement of particles upon loading lead to their breakage (Indraratna et al. 2005 and Lackenby et al. 2007), the extent of which directly determines the design life of ballast. Therefore, it is essential to lessen the particle breakage to enhance the ballast life, and thereby minimise the need for frequent ballast replacements. In this context, the placement position of geogrid was altered within the test tank to study its possible effect on the particle degradation.

A significant variation in the $B B I$ is witnessed as the placement position of geogrid is altered (Figure 6a). For instance, the geogrid G3 when placed at 0, 65, 130 and $195 \mathrm{~mm}$ above the subballast-ballast interface exhibits a $B B I$ of $6.49,4.80,4.66$ and $6.11 \%$ respectively. The reduction in $B B I$ from 6.49 to $4.8 \%$ as the position of geogrid is changed from 0 to $65 \mathrm{~mm}$ above the subballast may be attributed to the better ballast-geogrid interaction, as the ballast particles now have the scope to protrude through the geogrid apertures in contrast to when placed directly over a dense and compacted layer of subballast. When the reinforcement is placed $130 \mathrm{~mm}$ above the subballast, the non-displacement boundary conditions imposed by geogrid extend on both sides of it thereby further reducing the extent of breakage to $4.66 \%$. However, as the position of reinforcement is further elevated to $z=195 \mathrm{~mm}$ the extent of $B B I$ increases again to $6.11 \%$. This is because the geogrid now gets into the zone close to the applied load wherein intense particle movement occurs which adversely affects the intensity of ballast-geogrid interaction. Figure 6(a) clearly depicts the optimum geogrid placement position to be $130 \mathrm{~mm}$ above the subballast to minimise the particle degradation. For 
practical purposes, geogrid can be positioned at $65 \mathrm{~mm}$ above the subballast as the increase in breakage $(B B I)$ is insignificant. For all positions of geogrid, the extent of breakage of bigger sized particles (i.e. $>37 \mathrm{~mm}$ ) effectively governs the degree of overall ballast breakage, $B B I$ (Figure 6b; after Marsal 1967). For instance, a reduction in breakage of particles of sizes > 37 $\mathrm{mm}$ (Figure $6 \mathrm{~b}$ ) in case of geogrid placed at $130 \mathrm{~mm}$ eventually leads to reduced $B B I$ as well (Figure 6a). Here, $\Delta W_{k}$ is the difference in percentage retained before and after testing. A closer look at Figure 6(b), that shows the variation in the extent of particle breakage with respect to their sizes, reveals that the particles bigger than $37 \mathrm{~mm}$ experience a greater extent of breakage in comparison to smaller sizes. This is because the bigger particles generally take up the entire applied load while smaller particles only fill up the voids. Moreover, bigger particles naturally contain higher micro-cracks as well (Lade et al. 1996) that make them more vulnerable to breakage. On the other hand, particles smaller than $26.5 \mathrm{~mm}$ show an increase in their percentage $\left(-\Delta W_{k}\right)$ as broken fragments from bigger particles fall in this size range.

\section{Stress distribution along the ballast depth}

Rapid-response hydraulic earth pressure cells having a diameter of $230 \mathrm{~mm}$ and thickness of $12 \mathrm{~mm}$ were placed centrally at the sleeper-ballast interface and at the subballast-ballast interface to establish the role of geogrid on the vertical stress variation along the ballast depth. This kind of pressure cells with grooved thick active faces based on semiconductor type transducers were successfully used in the past by Indraratna et al. (2010 \& 2011) and Nimbalkar et al. (2014) to measure the vertical and horizontal stresses in ballast. It is seen from Figure 7 that the magnitude of applied vertical stress on ballast gets significantly reduced at the ballast-subballast interface. For instance, the stress at the ballast-subballast interface is only $220 \mathrm{kPa}$ in comparison to the applied vertical stress of $460 \mathrm{kPa}$. A similar pattern of reduction in stress along the ballast depth was demonstrated earlier by Indraratna et al. (2010) based on the field studies. The primary reason behind the reduction in stress, as expected, is the dispersion of load over a wider area with depth of ballast. The energy dissipation because of the particle rearrangement and their breakage also contributes towards the stress reduction. The inclusion of geogrid G1and G4 within the ballast helps reducing the applied stress further to about 170 and $151 \mathrm{kPa}$ at the said interface, which is only about $35 \%$ of the original stress. In case of reinforced ballast, the straining of geogrid leads to a higher reduction in stress which is also supplemented by reduced extent of particle degradation and 
deformations (Figures 3-5). These findings point out that geogrid reduces the subgrade stresses while still maintaining the track alignment, thereby making it an attractive solution to tackle the track problems.

\section{Conclusions}

This paper presented the results from large-scale cyclic tests carried on geogrid-reinforced ballast using the LPSA apparatus. The results from the study established the novel FBG sensing system to be effective in precisely capturing the internal lateral deformations in ballast under cyclic loading. Unlike the conventional LVDTs, the FBG sensors due to their high resolution also captured the minor fluctuations in lateral strains in ballast. The geogrid was found to be effective in inhibiting both the lateral as well as vertical deformations in ballast. For instance, the geogrid G4 reduced the lateral spreading at the subballast-ballast interface from 18 to $6.8 \mathrm{~mm}$. Similarly, the total vertical settlements in ballast were successfully reduced from $23.5 \mathrm{~mm}$ to $13.2 \mathrm{~mm}$. The settlement in both unreinforced and geogrid-reinforced ballast was shown to be governed by a logarithmic relation (Equation 3). Moreover, the vertical strain in subballast layer was observed to be only about $3 \%$ in comparison to that of about $7.25 \%$ in ballast. This observation points out that the benefits of geogrid would be higher when placed in ballast rather than subballast.

In comparison to an initial coefficient of uniformity $\left(c_{u}\right)$ of 1.87 , the $c_{u}$ of different ballast samples after the testing ranged from 1.89 to 1.94 which was well below the critical value to impede track drainage. The test results also proved beyond doubt that geogrid curtails the extent of particle breakage $(B B I)$. However, an optimum placement position of geogrid does exist to minimise the particle degradation, which was determined as $130 \mathrm{~mm}$ above the subballast. Furthermore, the data from pressure plates revealed that the applied vertical stress (i.e. sleeper-ballast contact stress) of $460 \mathrm{kPa}$ got reduced to $220 \mathrm{kPa}$ at the ballast-subballast interface. The inclusion of geogrid (G1 and G4) helped reducing the stress further to about 170 and $151 \mathrm{kPa}$ at this interface.

It is to be noted that manufacturers produce geogrids of different aperture sizes to serve different functions for wide variety of soils (not necessarily for ballast and subballast reinforcement). Therefore, extra care needs to be exercised in selecting geogrids for railroad 
applications as the smaller aperture sized geogrids will not establish proper geogrid-aggregate interlock.

\section{Acknowledgement}

This research was funded by the Cooperative Research Centre for Rail Innovation (established and supported under the Australian Government's Cooperative Research Centres program). The assistance of Technical Officers at the Centre of Geomechanics and Railway Engineering, University of Wollongong in the laboratory tests is highly appreciated. Our thanks are also due to the anonymous reviewers for their valuable comments and suggestions to improve the quality of the paper.

\section{References}

AS 2758.7. Aggregates and Rock for Engineering Purposes, Part 7: Railway Ballast. Standards Association of Australia, NSW; 1997.

Aursudkij B, McDowell GR, Collop AC. Cyclic loading of railway ballast under triaxial conditions and in a railway test facility. Granular Matter 2009; 11(6): 391-401.

Baessler M, Rucker W. Track settlement due to cyclic loading with low minimum pressure and vibrations. In: System dynamics and long-term behaviour of railway vehicles, Track and subgrade, Popp K, and SchiehlenW. (Editors), Springer, Berlin 2003; 337-356.

Bathurst RJ, Raymond GP. Geogrid reinforcement of ballasted track. In: Transportation Research Record, National Research Council, Transportation Research Board 1987; 1153:814.

Chen C. Discrete element modelling of geogrid-reinforced railway ballast and track transition zones, PhD thesis 2013; University of Nottingham.

Dash SK, Shivadas AS. Performance Improvement of Railway Ballast Using Geocells. Indian Geotechnical Journal 2012; 42(3):186-193 (DOI 10.1007/s40098-012-0017-3).

Dijcker R, Wijk MVD, Artières O, Dortland G, Lostumbo J. Geotextile Enabled Smart Monitoring Solutions for Safe and Effective Management of Tailings and Waste Sites, Two case studies: Volgermeerpolder (The Netherlands) and Suncor (Canada). Proceedings Tailings and Mine Waste, Vancouver, BC, Nov $6^{\text {th }}$ to $9^{\text {th }}, 2011$.

Fernandes G, Palmeira EM, Gomes RC. Performance of geosynthetic-reinforced alternative sub-ballast material in a railway track. Geosynthetics International 2008, 15 (5), 311-321. 
Fernandez-Vallejo M, Rota-Rodrigo S, Lopez-Amo M. Remote $(250 \mathrm{~km})$ Fiber Bragg Grating Multiplexing System. Sensors 2011; 11, 8711-8720; doi:10.3390/s110908711.

Ferellec JF, McDowell, GR. A method to model realistic particle shape and inertia in DEM. Granular Matter 2010; 12, 459-467.

Guo H, Xiao G, Mrad N, Yao J. Fiber Optic Sensors for Structural Health Monitoring of Air Platforms. Sensors 2011; 11, 3687-3705.

Hussaini SK Karimullah. An Experimental Study on the Deformation Behaviour of Geosynthetically Reinforced Ballast. PhD Thesis, 2013, University of Wollongong, Australia. Hussaini SK Karimullah, Indraratna B, Jayan S Vinod. Performance assessment of geogridreinforced railroad ballast during cyclic loading. Transportation Geotechnics 2015a; 2, 99107. (Doi: http://dx.doi.org/10.1016/j.trgeo.2014.11.002).

Hussaini SK Karimullah, Indraratna B, Vinod Jayan S. Application of Optical-Fiber Bragg Grating Sensors in Monitoring the Rail Track Deformations. Geotechnical Testing Journal, ASTM 2015b; 38(4), 387-396, doi: 10.1520/GTJ20140123. ISSN 0149-6115.

Indraratna B, Khabbaz H, Salim W, Lackenby J, Christie D. Ballast characteristics and the effects of geosynthetics on rail track deformation. Int. Conference on Geosynthetics and Geoenvironmental Engineering, Mumbai, India 2004; 3-12.

Indraratna B, Lackenby J, Christie D. Effect of confining pressure on the degradation of ballast under cyclic loading. Geotechnique 2005; 55(4): 325-328.

Indraratna B, Shahin M, Rujikiatkamjorn C. Stabilisation of ballasted rail tracks and underlying soft formation soils with geosynthetic grids and drains, ASCE Special Geotechnical Publication No. 152, Proceedings of Geo-Shanghai 2006; 152:143-152.

Indraratna B, Nimbalkar S, Christie D, Rujikiatkamjorn C, Vinod JS. Field Assessment of the Performance of a Ballasted Rail Track with and without Geosynthetics. Journal of Geotechnical and Geoenvironmental Engineering 2010; 136(7): 907-917.

Indraratna B, Salim W, Rujikiatkamjorn C. Advanced rail geotechnology- ballasted track. The Netherlands: CRC Press/Balkema, 2011.

Indraratna B, Syed KK Hussaini, Vinod JS. On the shear behavior of ballast-geosynthetic interfaces. Geotechnical Testing Journal, ASTM 2012; 35(2): 305-312 (DOI: 10.1520/GTJ103317).

Indraratna B, Syed KK Hussaini, Vinod JS. The lateral displacement response of geogridreinforced ballast under Cyclic Loading. Geotextiles and Geomembranes 2013; 39: 20-29. 
Lackenby J, Indraratna B, McDowell G, Christie D. Effect of confining pressure on ballast degradation and deformation under cyclic triaxial loading. Geotechnique 2007; 57 (6): 527536.

Lade PV, Yamamuro, JA, Bopp PA. Significance of particle crushing in granular materials. Journal of Geotechnical Engineering, ASCE 1996; 122 (4): 309-316.

Lee KY, Lee KK, Ho SL. Exploration of Using FBG Sensor for Axle Counter in Railway Engineering. WSEAS Transactions on Systems 2004b; 6(3): 2440-2447.

Le Pen L. Track behaviour: The importance of the sleeper to ballast interface. $\mathrm{PhD}$ Thesis 2008. University of Southampton, UK.

Le Pen LM, Powrie W. Contribution of base, crib and shoulder ballast to the lateral sliding resistance of railway track: a geotechnical perspective. Proceedings of the Institution of Mechanical Engineers Part F: Journal of Rail and Rapid Transit 2011; 225(2): 113-128. http://dx.doi.org/10.1177/0954409710397094.

Liehr S, Lenke P, Krebber K, Seeger M, Thiele E, Metschies H, Gebreselassie B, Münich, JC, Stempniewski L. Distributed strain measurement with polymer optical fibers integrated into multifunctional geotextiles. Proc. of SPIE 2008; Vol. 7003, 700302(1-15).

Matharu MS. Geogrid cut ballast settlement rate on soft substructures. Railway Gazette International 1994; 150(3): 165-166.

McDowell GR, Lim WL, Collop AC, Armitage R, Thom NH. Comparison of ballast index tests with performance under simulated train loading and tamping. Proceedings of the Institution of Civil Engineers-Geotechnical Engineering 2004a; 157(3): 151-161.

McDowell GR, Buchanan J, Lim WL. Performance of ballast mixtures. Ground Engineering 2004b; 37(10): 28-31.

Micron Optics, Inc. Si 425 Optical Sensing Interrogator Instruction Manual. Atlanta, USA 2007.

Mihailov SJ. Fiber Bragg Grating Sensors for Harsh Environments. Sensors (Basel) 2012; 12(2), pp. 1898-1918. (DOI: 10.3390/s120201898).

Nancey A, Imbert B, Robinet A. Thick and abrasion resistant geotextile for use under the ballast in railway structures. $7^{\text {th }}$ International Conference on Geosynthetics, Nice, France $2002 ; 3,1191-1194$.

Nöther N, Glötzl R, Vollmert L, Ehrenberg H, Weisemann U, Großmann S, Oehmichen R. Displacement Monitoring in Geotechnical Applications Using Optical Fiber Sensors in Geosynthetics. $6^{\text {th }}$ European Workshop on Structural Health Monitoring - We.2.C.4, 2012. 
Raymond GP, Bathurst RJ. Performance of large-scale model single tie ballast systems. Transportation Research Record 1987; 1131, 7-14.

Raymond GP, Bathurst RJ. Repeated-load response of aggregates in relation to track quality index Canadian Geotechnical Journal 1994; 31(4), 547-554, (DOI: 10.1139/t94-063).

Rowe RK, Gnanendran CT. Geotextile Strain in a Full Scale Reinforced Test Embankment. Geotextiles and Geomembranes 1994; 13, 781-806.

Selig ET, Waters JM. Track geotechnology and substructure management. Thomas Telford Services Ltd., London, UK. 1994.

Tam HY, Lee T, Ho SL, Haber T, Graver T, M'endez A. Utilizatization of fiber optic Bragg grating sensing system for health monitoring of railway applications. In: Structural Health Monitoring: Quantification, Validation, Implementation, F.-K. Chang, Ed. 2007; vol. 1, 1824-1831.

Weng X, Wang W. Influence of differential settlement on pavement structure of widened roads based on large-scale model test. Journal of Rock Mechanics and Geotechnical Engineering 2011; 3(1): 90-96.

Yoon HJ, Song KY, Kim JS, Kim DS. Longitudinal strain monitoring of rail using a distributed fiber sensor based on Brillouin optical correlation domain analysis. NDT\&E International 2011; 44, 637-644.

Zhu H. Fiber optic monitoring and performance evaluation of geotechnical structures. PhD Thesis 2009, The Hong Kong Polytechnic University, Hong Kong.

\section{Notation}

$A_{t} \quad$ axle load in tons

$B B I$ ballast breakage index

$C_{m} \quad$ the number of load cycles/MGT

$C_{u f} \quad$ coefficient of uniformity (after the testing)

$D_{50} \quad$ mean particle size of ballast

$D_{\max } \quad$ maximum particle size of ballast

$F B G \quad$ fiber Bragg grating

LPSA large process simulation apparatus

$N_{a} \quad$ the number of axles/load cycle

$N \quad$ number of load cycles

PSD particle size distribution

Z distance above the subballast 
$e_{f} \quad$ void ratio

$\alpha, \beta$ empirical constants

$\lambda_{b} \quad$ Bragg wavelength

$n_{e} \quad$ effective refractive index

$\Lambda \quad$ grating period

\section{List of Tables}

Table 1 Physical and technical properties of the geogrids used in the current study (after Indraratna et al. 2012)

Table 2 Placement location of FBG sensors above the subballast along with their wavelengths (after Hussaini et al. 2015b)

Table 3 Values of empirical coefficients $\alpha$ and $\beta$ of different ballast samples

Table 4 Coefficient of uniformity $C_{u f}, B B I(\%)$, and void ratio $\left(e_{f}\right)$ of different ballast samples after the testing

\section{List of Figures}

Figure 1 (a) Schematic diagram showing five movable plates of the LPSA along with the placement location of the sensing sheet embedded with 4-FBG sensors within the test tank, and (b) Particle size distribution (PSD) of the ballast and subballast used in the study (Hussaini 2013).

Figure 2(a) A photograph of the ballast sample with settlement pegs and sensing sheet installed in the test apparatus ready for testing, (b) A photograph of the geogrid G3 used in the study (c) Optical fiber with FBG sensor embedded in it.

Figure 3 Variation of lateral strains in FBG sensors and the corresponding lateral displacements ${ }^{*}$ based on plate movement in unreinforced and geogrid-reinforced ballast (G4 at $z=0 \mathrm{~mm}$ ) with $N$, for FBGs located at (a) $284 \mathrm{~mm}$ (b) $203 \mathrm{~mm}$ (c) $122 \mathrm{~mm}$ and (d) $41 \mathrm{~mm}$ above the subballast. * Lateral displacement (LVDT) data sourced from Indraratna et al. (2013).

Figure 4 Variation of total vertical settlement with number of load cycles, $N$ for (a) ballast and (b) subballast layers.

Figure 5 PSD of ballast reinforced with geogrid G3 before and after the testing. 
Figure 6 (a) Variation of $B B I$ for geogrid (G3) placed at different distances above the subballast, (b) Variation of particle distribution with grain size for different placement positions of geogrid G3.

Figure 7 Distribution of applied vertical stress along the ballast depth for ballast with and without geogrids. 


\section{TABLES}

Table 1 Physical and technical properties of the geogrids used in the current study (after Indraratna et al. 2012)

\begin{tabular}{cccccccc}
\hline $\begin{array}{c}\text { Geogrid } \\
\text { type }\end{array}$ & $\begin{array}{c}\text { Aperture } \\
\text { shape }\end{array}$ & $\begin{array}{c}\text { Aperture size } \\
(\mathrm{mm})\end{array}$ & $\begin{array}{c}\text { Rib thickness } \\
(\mathrm{mm})\end{array}$ & $T_{\text {ult }}{ }^{\#}(\mathrm{kN} / \mathrm{m})$ \\
\cline { 3 - 8 } & & $\mathrm{MD}$ & $\mathrm{CMD}$ & $\mathrm{MD}$ & $\mathrm{CMD}$ & $\mathrm{MD}$ & $\mathrm{CMD}$ \\
\hline$G 1$ & Square & 38 & 38 & 2.2 & 1.3 & 30 & 30 \\
G2 & Triangle & 36 & 36 & 2.0 & 2.0 & 19 & 19 \\
G3 & Square & 65 & 65 & 1.7 & 1.5 & 30 & 30 \\
G4 & Rectangle & 44 & 42 & 1.0 & 1.0 & 30 & 30
\end{tabular}

MD-Machine direction; CMD-Cross machine direction; " Ultimate tensile strength (manufacturer supplied values).

Table 2 Placement location of FBG sensors above the subballast along with their wavelengths (after Hussaini et al. 2015b)

\begin{tabular}{cccccc}
\hline Sensor & Position above & \multicolumn{4}{c}{ Wavelength $(\mathrm{nm})$} \\
\cline { 3 - 6 } No. & subballast $(\mathrm{mm})$ & $\mathrm{UR}, \mathrm{G}^{*}, \mathrm{G} 1^{*}$ & $\mathrm{G1}^{+}, \mathrm{G}^{+}$ & $\mathrm{G}^{+}, \mathrm{G}^{*}$ & $\mathrm{G3}^{+}, \mathrm{G}^{*}$ \\
\hline FBG-1 & 41 & 1555 & 1560 & 1560 & 1555 \\
FBG-2 & 122 & 1545 & 1560 & 1550 & 1550 \\
FBG-3 & 203 & 1535 & 1555 & 1540 & 1535 \\
FBG-4 & 284 & 1535 & 1535 & 1535 & 1535 \\
\hline
\end{tabular}

Geogrid placement position: ${ }^{*}$ Subballast-ballast interface (i.e. $z=0 \mathrm{~mm}$ ); ${ }^{+} 65 \mathrm{~mm}$ above the subballast (i.e. $z=65 \mathrm{~mm}$ ).

Table 3 Values of empirical coefficients $\alpha$ and $\beta$ of different ballast samples

\begin{tabular}{cccccccccc}
\hline Parameter & UR & G1* & G2* & $\mathrm{G}^{*}$ & $\mathrm{G}^{*}$ & $\mathrm{G1}^{+}$ & $\mathrm{G}^{+}$ & $\mathrm{G3}^{+}$ & $\mathrm{G}^{+}$ \\
\hline $\boldsymbol{\alpha}$ & 1.52 & 1.04 & 1.15 & 0.96 & 0.71 & 0.71 & 1.62 & 0.74 & 0.59 \\
$\boldsymbol{\beta}$ & 5.70 & 4.419 & 6.25 & 3.55 & 4.15 & 4.35 & 9.15 & 1.99 & 3.05 \\
$\boldsymbol{R}^{2}$ & 0.98 & 0.95 & 0.93 & 0.97 & 0.94 & 0.86 & 0.90 & 0.94 & 0.94
\end{tabular}

Geogrid placement position: ${ }^{*}$ Subballast-ballast interface (i.e. $z=0 \mathrm{~mm}$ ); ${ }^{+} 65 \mathrm{~mm}$ above the subballast (i.e. $z=65 \mathrm{~mm}$ ). 
Table 4 Coefficient of uniformity $C_{u f}, B B I(\%)$, and void ratio $\left(e_{f}\right)$ of different ballast samples after the testing

\begin{tabular}{cccccccccc}
\hline Parameter & $\mathrm{UR}$ & $\mathrm{G} 1^{*}$ & $\mathrm{G} 2 *$ & $\mathrm{G} 3 *$ & $\mathrm{G} 4^{*}$ & $\mathrm{G}^{+}$ & $\mathrm{G}^{+}$ & $\mathrm{G}^{+}$ & $\mathrm{G}^{+}$ \\
\hline $\boldsymbol{C}_{u f}$ & 1.93 & 1.92 & 1.93 & 1.93 & 1.92 & 1.92 & 1.94 & 1.89 & 1.89 \\
$\boldsymbol{B B I}^{\#}(\boldsymbol{\%})$ & 9.89 & 7.78 & 8.91 & 6.49 & 6.29 & 5.99 & 11.00 & 4.80 & 4.60 \\
$\boldsymbol{e}_{f}$ & 0.65 & 0.69 & 0.68 & 0.69 & 0.70 & 0.71 & 0.64 & 0.71 & 0.71
\end{tabular}

Geogrid placement position: ${ }^{*}$ Subballast-ballast interface (i.e. $z=0 \mathrm{~mm}$ ); ${ }^{+} 65 \mathrm{~mm}$ above the subballast (i.e. $z=65 \mathrm{~mm}) .{ }^{\#} B B I$ data sourced from Indraratna et al. (2013). 


\section{FIGURES}

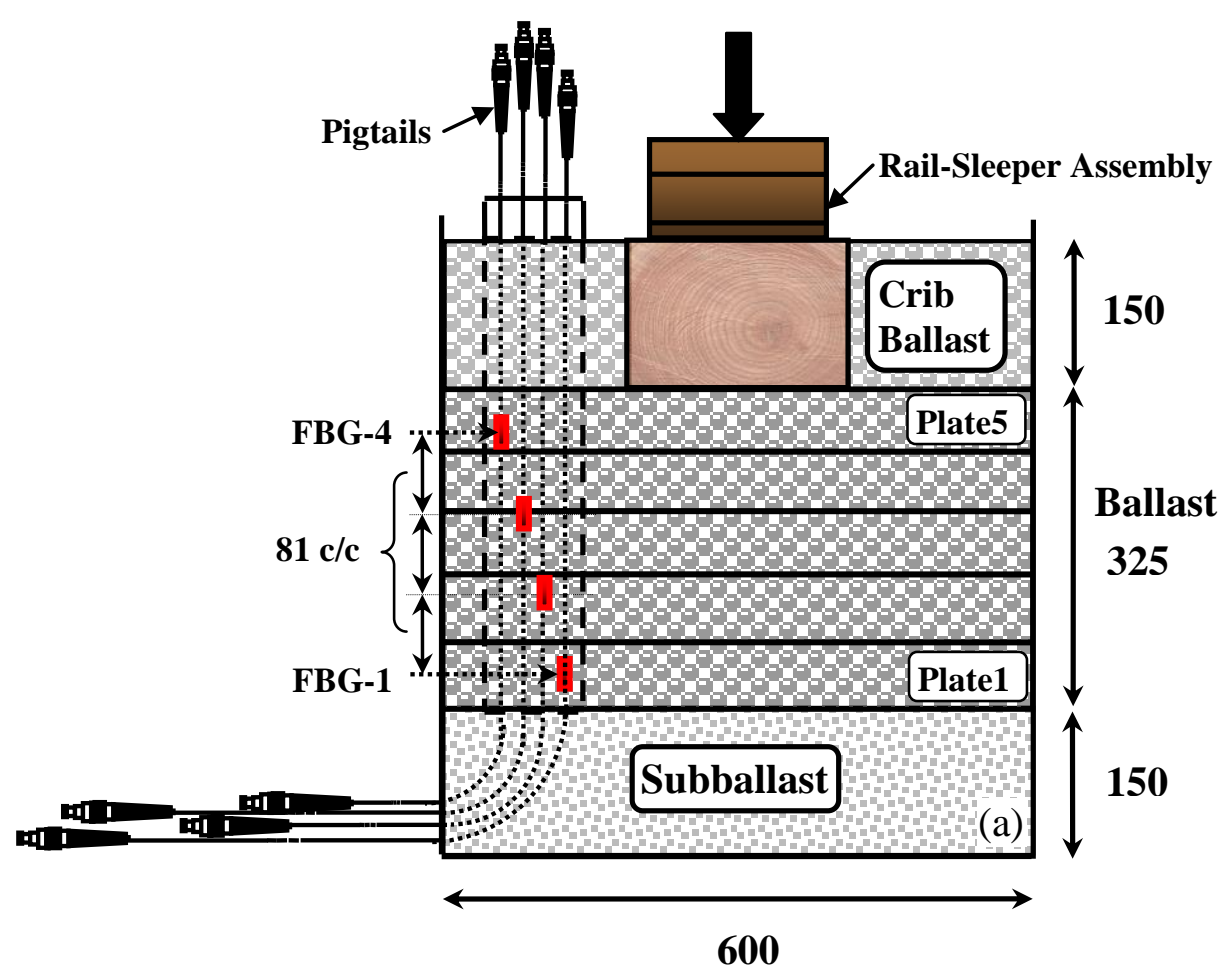

All dimensions in mm

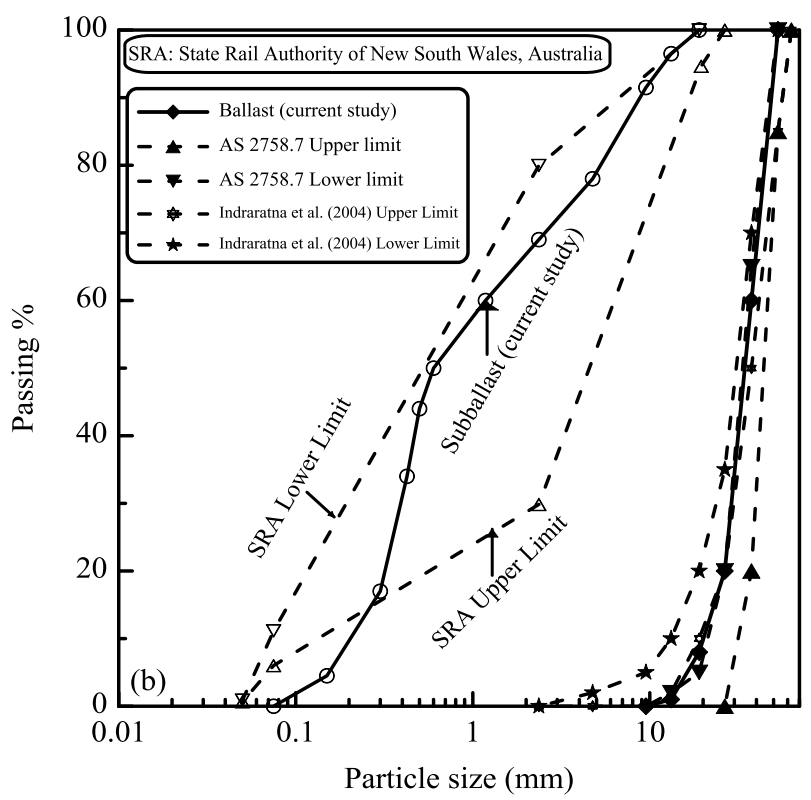

Figure 1 (a) Schematic diagram showing five movable plates of the LPSA along with the placement location of the sensing sheet embedded with 4-FBG sensors within the test tank, and (b) Particle size distribution (PSD) of the ballast and subballast used in the study (Hussaini 2013). 

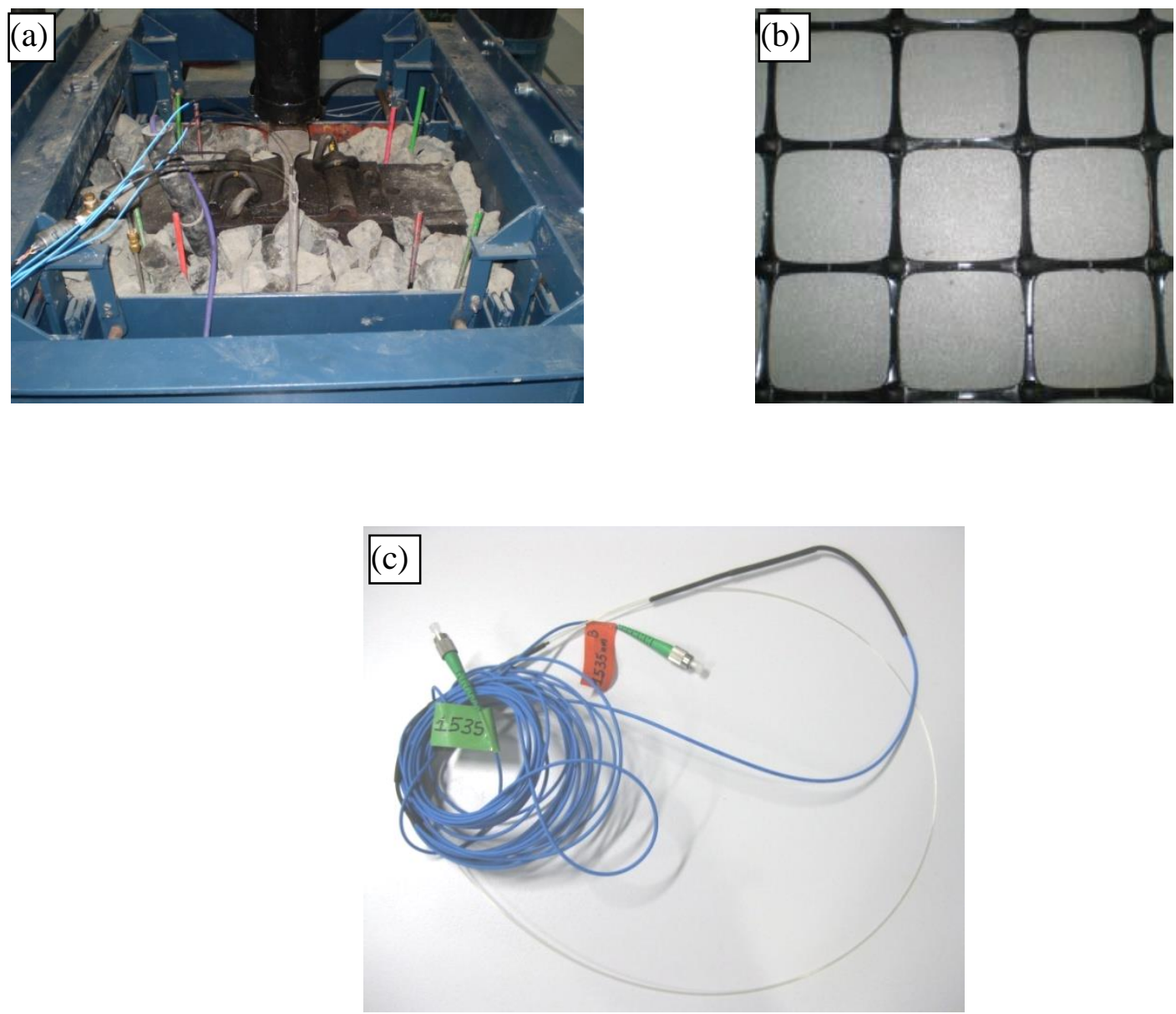

Figure 2(a) A photograph of the ballast sample with settlement pegs and sensing sheet installed in the test apparatus ready for testing, (b) A photograph of the geogrid G3 used in the study (c) Optical fiber with FBG sensor embedded in it. 

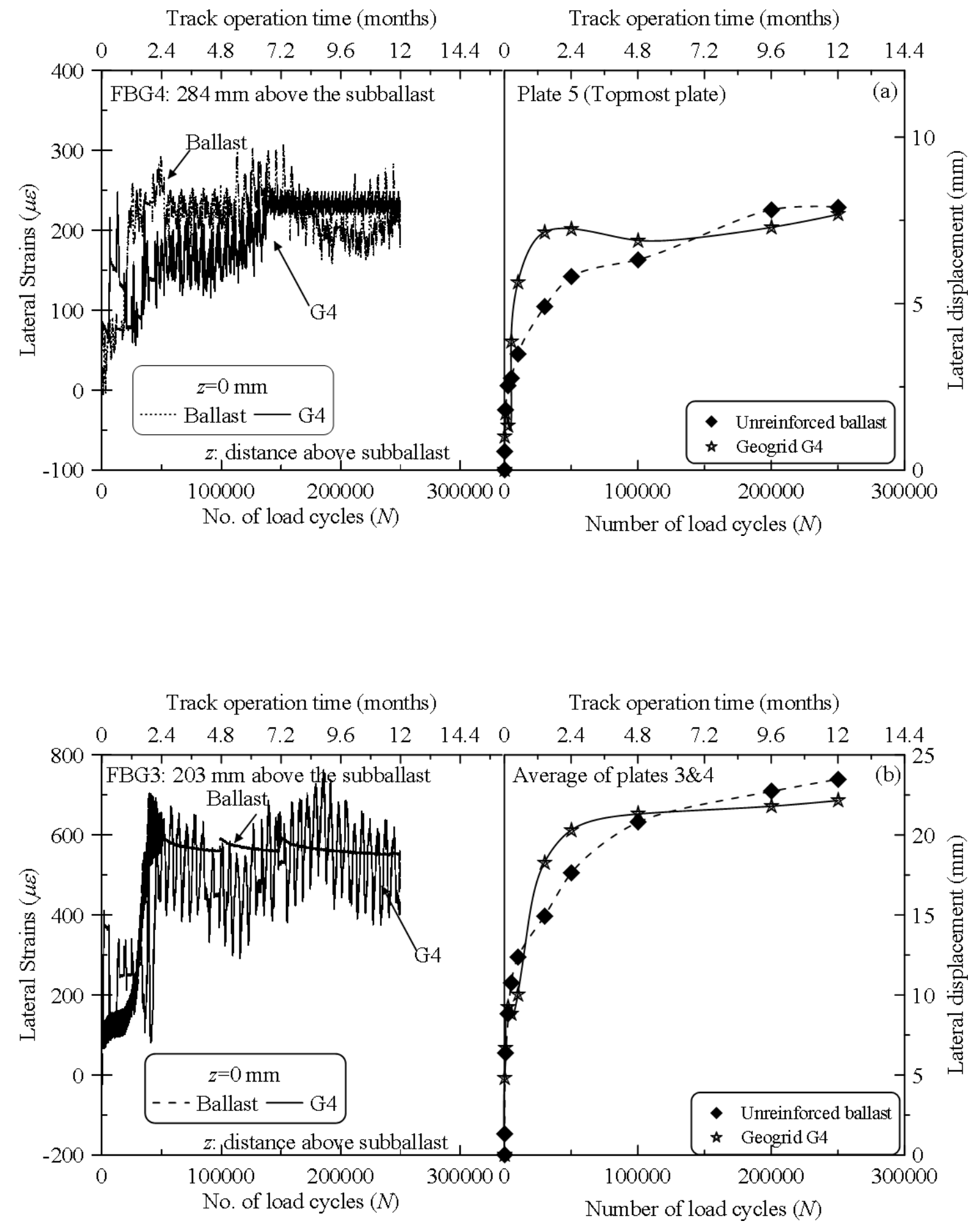

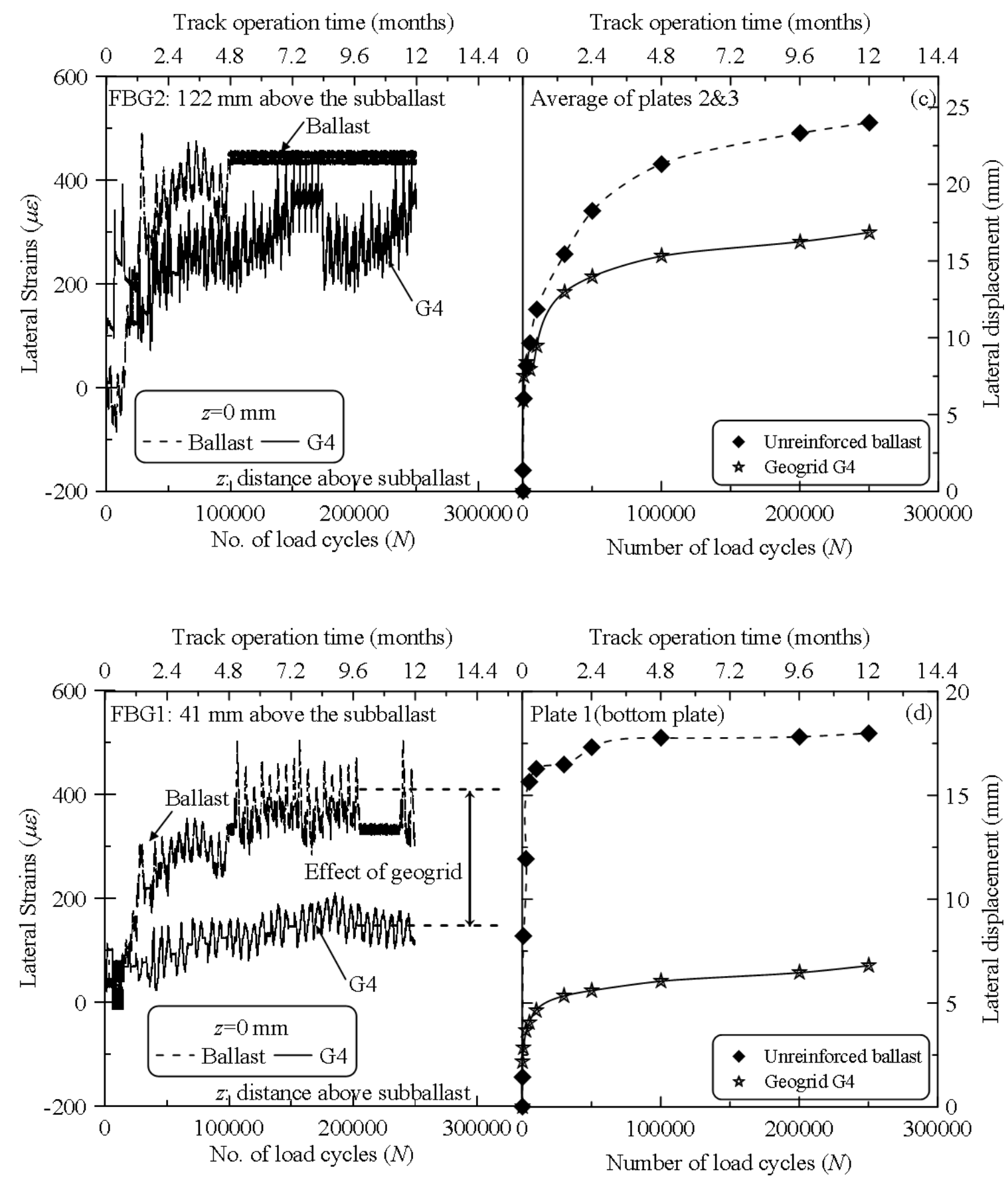

Figure 3 Variation of lateral strains in FBG sensors and the corresponding lateral displacements ${ }^{*}$ based on plate movement in unreinforced and geogrid-reinforced ballast (G4 at $z=0 \mathrm{~mm}$ ) with $N$, for FBGs located at (a) $284 \mathrm{~mm}$ (b) $203 \mathrm{~mm}$ (c) $122 \mathrm{~mm}$ and (d) $41 \mathrm{~mm}$ above the subballast. "Lateral displacement (LVDT) data sourced from Indraratna et al. (2013). 

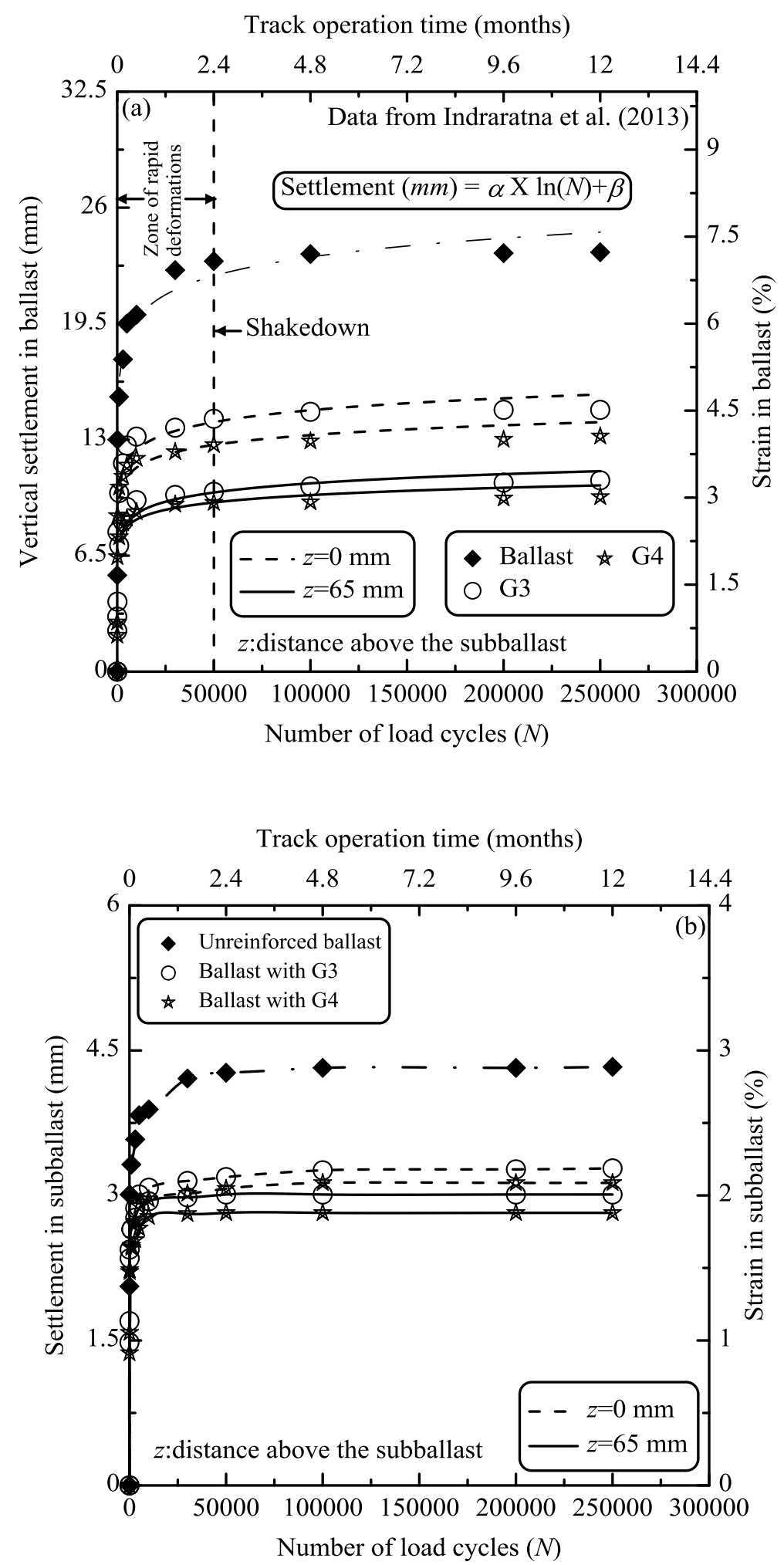

Figure 4 Variation of total vertical settlement with number of load cycles, $N$ for (a) ballast and (b) subballast layers. 


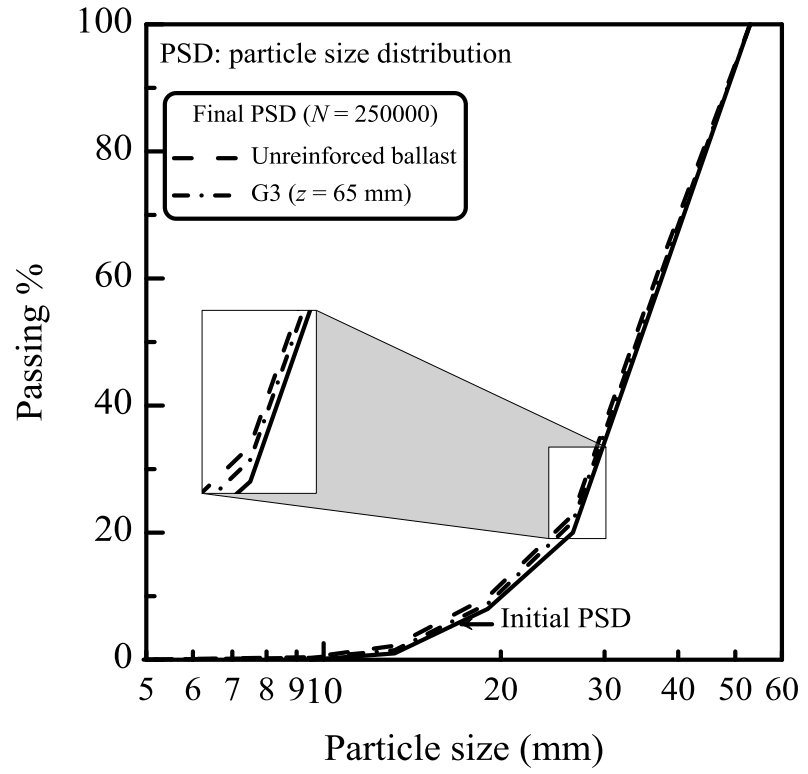

Figure 5 PSD of ballast reinforced with geogrid G3 before and after the testing.
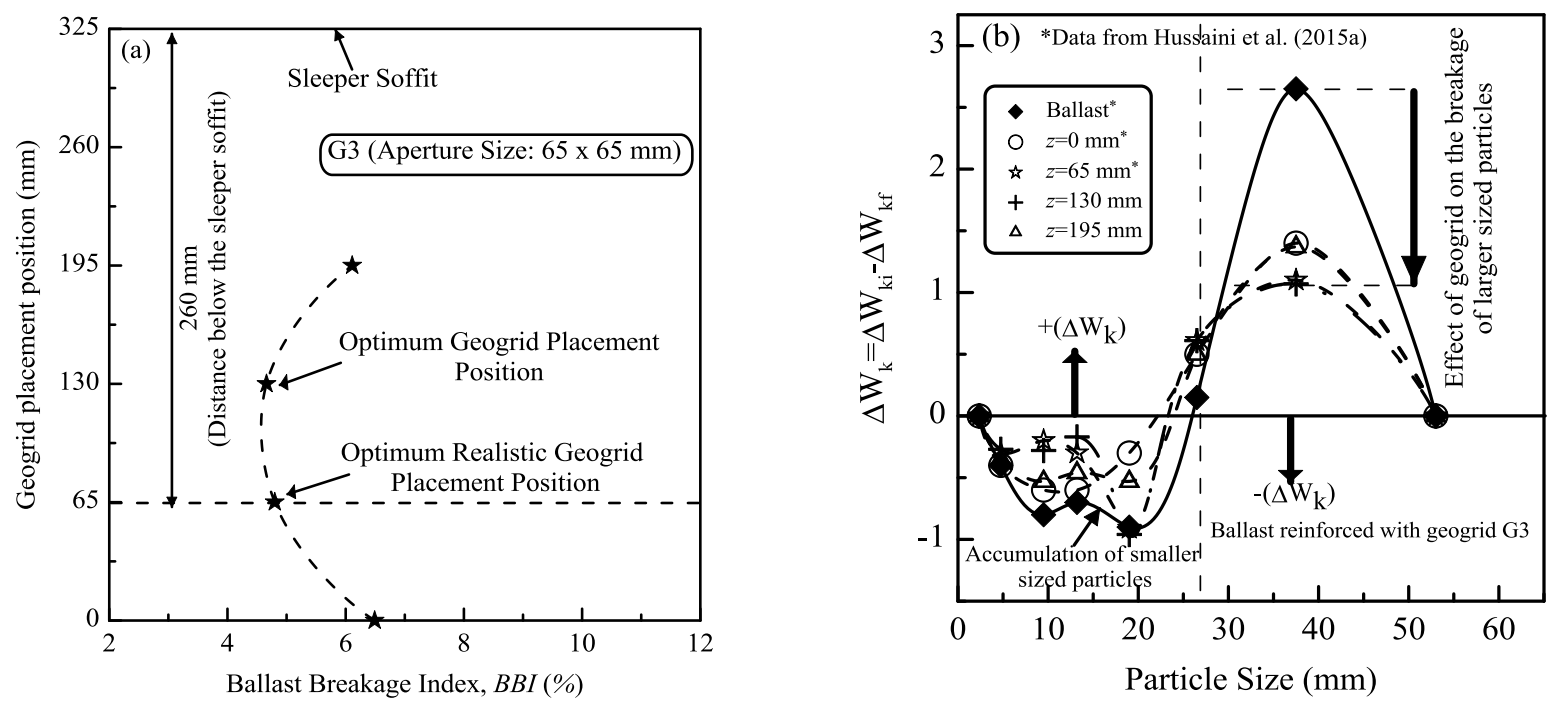

Figure 6 (a) Variation of $B B I$ for geogrid (G3) placed at different distances above the subballast, (b) Variation of particle distribution with grain size for different placement positions of geogrid G3. 


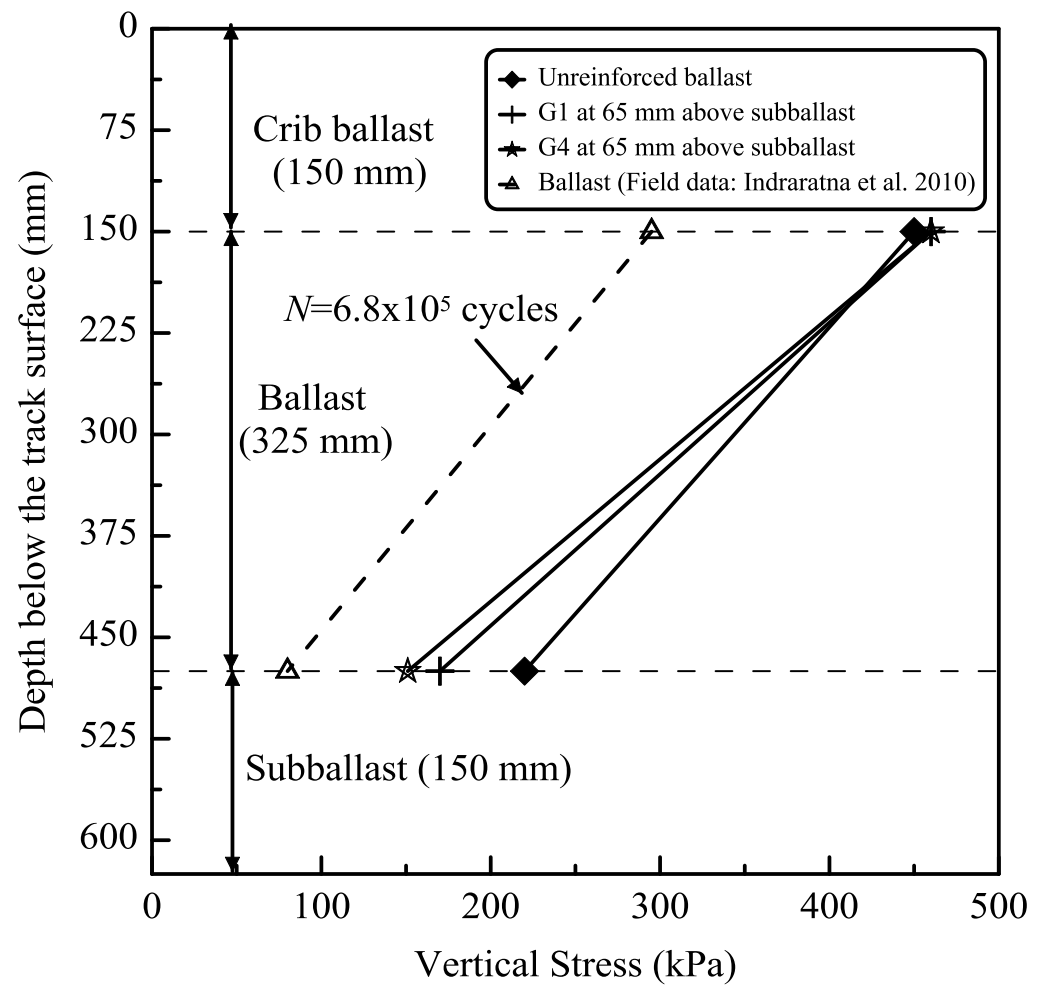

Figure 7 Distribution of applied vertical stress along the ballast depth for ballast with and without geogrids. 